\title{
Cartas al Director
}

\section{Cistoadenocarcinoma hepático. Diagnóstico diferencial de tumores quísticos hepáticos}

Palabras clave: Cistoadenocarcinoma. Hígado. Cirugía radical.

Key words: Cystoadenocarcinoma. Liver. Radical surgery.

\section{Sr. Director:}

Los cistoadenomas $(\mathrm{CH})$ y los cistoadenocarcinomas hepáti$\cos (\mathrm{CCH})$ son raras neoplasias quísticas que se originan en el epitelio biliar y que suponen menos del 5\% de las neoplasias quísticas del hígado. Son tumores cuyos síntomas son inespecíficos -dolor en hipocondrio derecho (HCD), náuseas, vómitosy más raramente producen clínica de obstrucción biliar. Hasta 2008 se han descrito en la literatura poco más de 100 casos (1). Presentamos el caso de un paciente con una tumoración quística en el hílio hepático que presenta datos sospechosos de malignidad.

\section{Caso clínico}

Varón de 52 años de edad, sin antecedentes de interés, estudiado por haberse encontrado en una ecografía abdominal por estudio urológico una tumoración quística intrahepática que en principio impresiona como quiste hepático complejo no complicado. Se solicita una TAC abdominal en la que se objetiva una imagen quística de unos 5 centímetros $(\mathrm{cm})$ de diámetro localizada entre los segmentos V y VIII con forma de racimo de uvas, septos en su interior, siendo alguno de ellos gruesos y

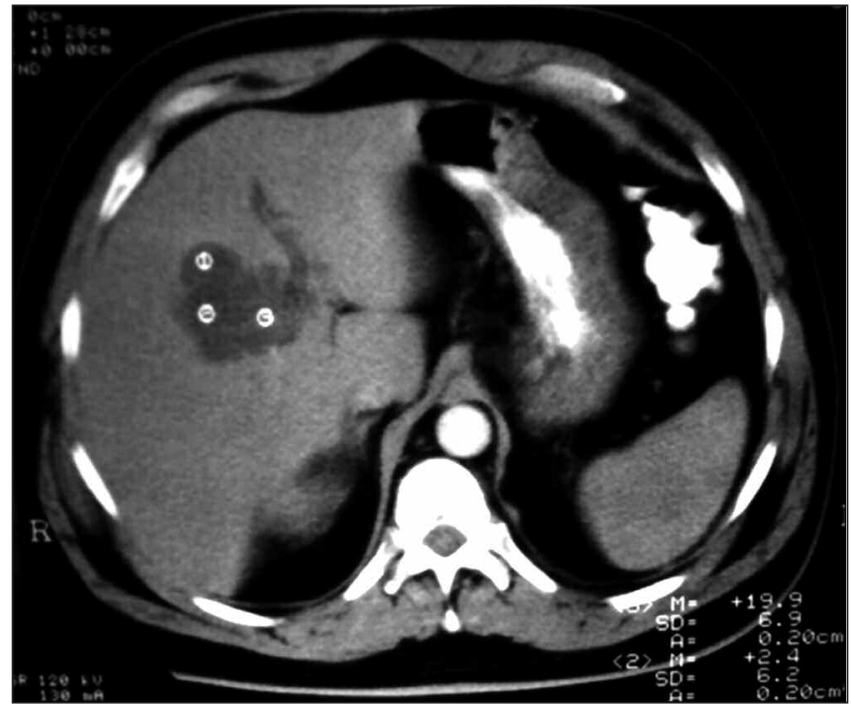

Fig. 1. Imagen radiológica de TAC: masa polilobulada situada en el hilio hepático.

captando contraste de forma significativa en algunas zonas. Los marcadores tumorales fueron negativos.

Dado el carácter asintomático del cuadro se decide seguimiento. En el control radiológico realizado al año se aprecia aumento del tamaño de la lesión $(9$ × 7 x 7 cm) estando situada en la confluencia porto-biliar, sin comprimir la misma. Ante el crecimiento de la lesión, se decide intervenir quirúrgicamente al paciente dadas las posibilidades de malignidad de la lesión (Fig. 1).

En la intervención quirúrgica se aprecia una tumoración localizada en la unión de los segmentos IV y V que abomba hacia el hilio, de aspecto quístico y polilobulada. La biopsia intraoperatoria es informada como tumor mucinoso sin poder descartarse malignidad.

Ante la posibilidad de encontrarnos ante un cistoadenocarcionoma, se decide excisión radical de la pieza, no pudiéndose realizar resección completa. En la disección se aprecia fistulización del tumor al conducto hepático derecho, salida de contenido mucinoso y lesiones polipoideas intraquísticas. 
El diagnóstico histológico definitivo resultó corresponder a un cistoadenocarcinoma mucosecretor que, al darse en un paciente varón, conlleva más agresividad.

La evolución ha sido favorable, recibiendo quimioterapia adyuvante con 5-fluorouracilo y encontrándose sin recidiva al año de seguimiento.

\section{Discusión}

El CCH es una neoplasia quística maligna del epitelio biliar cuya incidencia es del $0,41 \%$ (1). Se han descrito en la literatura menos de 200 casos de $\mathrm{CH}$ y algo más de la mitad de $\mathrm{CCH}$ $(1,2)$.

Su presentación clínica suele ser indistinguible de otras lesiones hepáticas $(1,3)$, aunque algunos permanecen sin diagnóstico hasta el estudio necrópsico (1). Su tamaño oscila entre 1,2 a $30 \mathrm{~cm}$ (1), pero su diámetro medio es de $12,4 \mathrm{~cm}$ (1). Las técnicas de imagen muestran una masa quística multilocular que frecuentemente presenta nódulos en la periferia de los septos (1-4). La presencia de septos internos aumenta la probabilidad del diagnóstico de $\mathrm{CCH}$, ya que el $\mathrm{CH}$ suele ser unilocular $(1,2)$.

La etiología del $\mathrm{CCH}$ no está todavía aclarada. Hay varias teorías. Algunas mantienen su origen en restos ectópicos embrionarios de vesícula biliar o conductos biliares (1-4). También se ha sugerido la posibilidad de originarse en un cistoadenoma previo (1-3). La demostración de epitelio benigno en el $90 \%$ de los cistoadenocarcinomas (1) convierte en muy probable esta teoría, además de estar descrita la transformación maligna en el $25 \%$ de los cistoadenomas (1), lo que apoya la actitud agresiva en casos de cistoadenomas. El desarrollo a partir de tejido ovárico ectópico parece poco probable (1) porque no hay descrito ningún caso que contenga folículos o sus derivados en los cistoadenocarcinomas con estroma mesenquimal.

Con un pronóstico mejor que el del hepatocarcinoma o del colangiocarcinoma $(1,4)$ la supervivencia global a los 3 años de los cistoadenocarcinomas resecados es del $75 \%$, en comparación con la del hepatocarcinoma (40\%) y la del colangiocarcinoma $(22 \%)(1)$.

Devaney y cols. (5) clasificaron este tumor en tres categorías en función de su pronóstico:

- Cistoadenocarcinoma con estroma mesenquimal originán- dose en un cistoadenoma previo. Se presenta en mujeres y tiene un curso relativamente indolente.

- Cistoadenocarcinoma sin estroma mesenquimal que no se asocia a su variante benigna. Ocurre en hombres y se acompaña de una evolución agresiva.

- Cistoadenocarcinoma sin estroma mesenquimal en mujeres, que presenta un curso clínico incierto.

Con curso clínico relativamente benigno es necesaria una resección completa para evitar recurrencias (1-4). Su excisión local produce recidiva tumoral en el $66 \%$ de casos frente a un $10 \%$ de aquellos que han sido completamente resecadas (1).

Durante la intervención quirúrgica es importante dejar los quistes intactos para evitar una carcinomatosis peritoneal.

En nuestro caso, es destacable que, a pesar de haberse realizado una resección incompleta, no se haya producido recidiva local del tumor, dado que la variante histológica es, según Devaney (5), la más agresiva de las tres.

C. Bernardos García, I. Alarcón del Agua, M. D. Casado Maestre, I. Serrano Borrero y J. M. Álamo Martínez

Servicio de Cirugía General y del Aparato Digestivo. Unidad de Cirugía Hepatobiliopancreática y Trasplante Hepático. Hospital Universitario Virgen del Rocío. Sevilla

\section{Bibliografía}

1. Lauffer JM, Baer HU, Maurer CA, et al. Biliary cystadenocarcinoma of the liver: the need for complete resection. Eur J Cancer 1998; 34(12): 1845-51.

2. Akiyoshi T, Yamaguchi K, Chijiiwa K, et al. Cystadenocarcinoma of the liver without mesenchymal stroma: possible progression from a benign cystic lesion suspected by follow-up imagings. J Gastroenterol 2003; 38(6): 588-92.

3. Bacher H, Cerwenka H, Werkgartner G, et al. Primary biliary cystadenocarcinoma perforating the duodenum and left intrahepatic biliary tree-mimicking a hydatid cyst. Liver 1999; 19: 39-41.

4. Shrikhande S, Kleeff J, Adyanthaya K, et al. Management of hepatobiliary cystadenocarcinoma. Dig Surg 2003; 20: 60-3.

5. Devaney K, Goodman ZD, Zshak KG. Hepatobiliary cystadenoma and cystadenocarcinoma: a light microscopic and immunohistochemical study of 70 patients. Am J Surg Pathol 1994; 18: 1078-91. 